\title{
İndüksiyon Bobin Tasarımında Kullanılan İletken Türlerinin İndüksiyon Sıvı Isıtıcı Performansına Etkilerinin Araştırılması
}

\author{
Ahmet ALTINTAŞ \\ Dumlupınar Üniversitesi, Simav Teknoloji Fakültesi, Elektrik-Elektronik Mühendisliği, 43500 Simav/Kütahya
}

\begin{abstract}
ÖZ
Sahip olduğu bazı üstünlükler dolayısıyla, indüksiyon prensibiyle sıvı 1sıtma sitemlerinin endüstriyel ve evsel kullanımı giderek artmaktadır. İndüksiyon siv1 1sıtma sistemlerinin en önemli unsurlarından biri indüksiyon bobinleridir. İndüksiyon bobinleri, rezonans durumunda en verimli çalıştıkları ve büyük akımlar taşıdıkları için, büyük kesitli iletkenlerden az sipirli sarılarak oluşturulurlar. Günümüzde, indüksiyon bobin tasarımında kullanılabilecek birçok iletken türü mevcuttur. Bu çalışmada, COMSOL ${ }^{\circledR}$ Multiphysics yazılımı kullanılarak, 8 farklı iletken türünden oluşturulan indüksiyon bobinlerinin 3B katı modelleri oluşturulmuş, eşit çevresel faktörler ve farklı çalışma frekansları için 2B manyetik ve termal analizleri gerçekleştirilmiş, 1sıtıcı aparat üzerinde açığa 1sıtma gücü hesaplanarak 1sıtıcı performans testi yapılmıştır. Bu çalışma aynı zamanda tasarımcı ve üretici firmalara, indüksiyon bobin tasarımında kullanılabilecek iletken türü seçiminde yardımcı olmayı da amaçlamaktadır.
\end{abstract}

Anahtar kelimeler: İndüksiyon sıvı 1sıtma, indüksiyon bobin tasarımı, manyetik analiz, Comsol.

\section{Investigating the Effects of Conductor Types of Induction Coil on Performance of the Induction Liquid Heater}

\begin{abstract}
In residential and industrial applications, the usage of induction liquid heater using induction heating principles is increasingly growing due to having some advantages. One of the components of the induction heating is induction coil. Because of working best at resonance condition and carrying a lot of current, induction coils are constituted from a wire having a big cross-sectional area; and also have a few turn. At present, there are a lot of wire types being used in induction coil design. In this study, by using the COMSOL ${ }^{\circledR}$ Multiphysics software, 3D solid models of a total of eight-induction-coil designed with different wire types are created; magnetic and thermal analysis of those are performed under identical environmental conditions for different working frequencies; and, performance tests of induction heaters are done by computing the heating-power on induction apparatus. This study, also, aims to help designer and manufacturer on choosing favorable wire type for induction coil design.
\end{abstract}

Keywords: Induction liquid heater, induction coil design, magnetic analysis, Comsol.

\section{GíRiş}

Günümüzde en yaygın ve en temiz enerji türlerinden olan elektrik enerjisi, ısıtma sistemlerinin vazgeçilmez bir unsurudur. Elektriksel 1sitma, genel olarak rezistif 1sitma ve indüksiyon 1sıtma olmak üzere iki ana başlik altında toplanabilir. Rezistif isitma sistemlerinde kullanilan temel unsur, krom-nikel telden imal edilen rezistanslardir. Rezistanslar, uygun güç ve şekillerde imal edilerek, gerekli 1Sı enerjisi elektrik şebekesinden kolaylıkla sağlanmış olur. Diğger bir elektriksel ısıtma yöntemi olan indüksiyon ısıtma, yüksek frekanslı alternatif akımın oluşturduğu manyetik alanın, 1sıtılacak parçalar üzerinde oluşturduğu histerezis ve eddy akımlarıyla sağlanmaktadır. İndüksiyon ısıtma sisteminin temel yapıtaşları, yüksek frekanslı alternatif akımı sağlayacak olan inverter ve manyetik alan kaynağı olan indüksiyon bobinidir [1-3].

Sabit duran ve/veya sürekli akan sıvıların ısıtılmasında her iki elektriksel 1sıtma yöntemini kullanmak mümkündür. Endüstriyel ve evsel sıv1 1sitma uygulamalarında rezistif ısıtma yöntemi, indüksiyon ısıtma yöntemine göre çok

Sorumlu yazar/Corresponding author: Ahmet Altıntaş, Tel: 0274 513759, e-posta: ahmet.altintas@dpu.edu.tr, Gönderilme/ Submitted: 11.03.2016, Kabul/Accepted: 03.04.2016 
daha pratik çözümler üretmektedir. Ancak, sıvıların 1sitılması için kullanılan rezistanslı 1sıtma yöntemlerinin bazı olumsuz yönleri vardır. Yüksek akış debili sistemlerde 1sıtma süresinin uzunluğu, su içinde bulunan kirecin çökelmesi sebebiyle oluşan kireçlenme problemleri, herhangi bir sebeple akışkan veya gövde üzerine olabilecek elektrik kaçağı riski, rezistansların sıvı içine konma zorunluluğu ve sıvı sızdırma problemleri bu sakıncalardan bazılarıdır. Rezistanslı sivi isitma sistemlerinin bu olumsuz etkilerini önlemek için günümüzde, indüksiyon 1sıtma prensibi ile çalışan düzenekler hakkında birçok çalışma gerçekleştirilmiştir. İndüksiyon 1sıtma teknolojisi, alış1lagelmiş 1sıtma sistemlerine göre; işlem süresinin oldukça kısa olması, dış çevreye 1sı dağılımının olmaması veya en az olması, yüksek verimliliği, yanma-patlama gibi olaylara izin vermeyen güvenilir bir sistem olmas1, elektriksel kaçak riskinin bulunmaması, sızdırmazlık problemlerinin ez az yaşanması gibi üstünlüklere sahiptir. $\mathrm{Bu}$ üstünlükler sayesinde indüksiyon 1sitma sistemlerinin endüstri ve ev tipi uygulamalarındaki kullanımı giderek artmaktadır [4-7]. İndüksiyon sivı 1sitma sistemine ait şematik bir gösterim Şekil.1'de verilmiştir. Şekil.1'e göre önce, şebekeden sağlanan AC enerji AC/DC konvertör ve filtre yardımıyla doğrultulmuş; sonra, DC/AC invertör yardımıyla yüksek frekanslı AC enerji elde edilip indüksiyon bobini beslenmiştir. İndüksiyon bobininin oluşturduğu yüksek frekanslı manyetik alan, sıvı akış yoluna ve bobin içine konumlandırılan ferromanyetik malzemeden üretilmiş aparatı ısıtarak akışkan sıvının 1sıtılması sağlanmıştır.

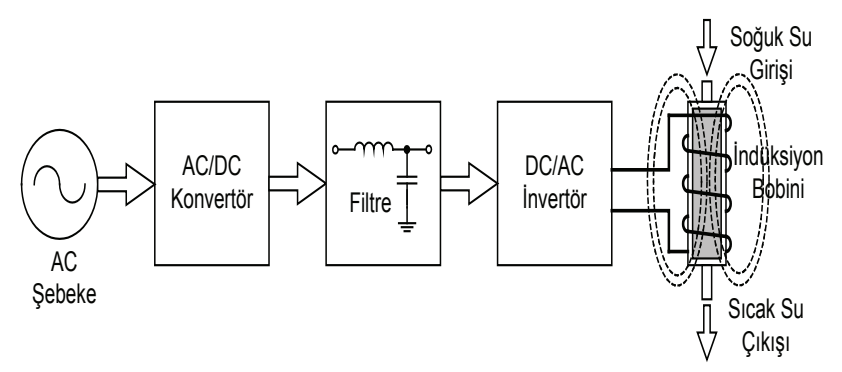

Şekil 1. İndüksiyon sıv1 1sıtma sistemine ait şematik bir gösterim

İndüksiyon sıvı 1sıtma sistemleri incelendiğinde, endirekt 1sıtma yönteminin kullanıldığı görülecektir; çünkü akışkan sıvılar (çoğunlukla su) genellikle paramanyetik veya diyamanyetik malzeme özelliğine sahiptir. $\mathrm{Bu}$ yüzden, değişken manyetik alan ile kolaylıkla 1sıtılabilen ferromanyetik malzemeler, indüksiyon isitıcılarda 1sitma aparatı olarak kullanılmakta ve endirekt 1sitma sağlamaktadır. Isıtma aparatları genel olarak iki ana gruba ayrılabilir: ferromanyetik malzemeden üretilmiş 1sıtıcı aparatın sıvı içine yüzer bir tarzda konumlandırıldığ 1 sistemler (yüzer tip) veya ferromanyetik malzemenin siviyı içine aldığı havuz tarzı sistemler (havuz tip) dir. Havuz tip indüksiyon 1sitıcıların, sürekli akan sıvıların 1sıtılmasındaki verimleri düşüktür; çünkü üretilen 1sı, deri etkisinden dolayı ısıtma aparatının dış yüzeyinde açığa çıkmakta ve bir miktar 1S1 dış ortama yayılmaktadır; ayrıca, dış ortama yayılan bu 1S1, bazı durumlarda indüksiyon bobinlerinin soğutulmasını da zorunlu kılmaktadır. Yüzer tip indüksiyon 1sıtıcılarda bu tür sakıncalar bulunmadığı için verimleri daha yüksektir.

İndüksiyon yöntemiyle sıvı 1sıtma hakkındaki çalışmalar 19801li yıllarda, yoğunluğu fazla olan sıvıların boru içindeki akışını hızlandırmak (sıvı viskozitesini arttırmak) için başlamıştır. Daha sonraki çalışmalar yüksek sıcaklıkta sıvı ve buhar elde etmek üzerine yoğunlaşmıştır. Havuz tip indüksiyon 1sıtma sistemini kullanan ilk çalışmalarda [8,9], boru içinden akan yağ ve su, sıvıları taşıyan ferromanyetik borular vasıtasıyla 1sıtılmıştır. Daha sonraki çalışmalarda, farklı geometrik şekillere sahip birçok yüzer tip indüksiyon ısıtma aparatları sunulmuştur; boru içindeki su akış yoluna yerleştirilen çelik levhalar [10], spiral biçiminde sarılıp iki ucu birleştirilmiş sac levha [11], delikli silindirik bloklar [12], yüzeyine sıvı akış kanalları açılmış silindirik parçalar [13], iç içe konumlandırılmış silindirik halkalar [14] bunlardan bazılarıdır.

Elektrik enerjisini ve elektriksel sinyalleri iletmek veya iki ve daha fazla sayıdaki elektriksel cihazı birbirine bağlamak için kullanılan, daha çok bakır ve alüminyum gibi elektriksel özellikleri iyi olan metallerden tek veya çok damarlı olarak üretilmiş malzemelere iletken veya kablo denilmektedir. Genel olarak kablolar, kullanılmış oldukları yerlere göre dört temel gruba ayrılabilir: Enerji kabloları, Kumanda ve sinyal kabloları, Telefon kabloları, Haberleşme kabloları. İndüksiyon 1sitıcıların en temel unsuru olan indüksiyon bobinleri, farklı tip enerji kablolarından imal edilebilirler. Çalışma prensibi gereği, yüksek akımlar taşıyacak olan indüksiyon bobinleri, büyük kesitlere sahip enerji kablolarından az sipirli olarak tasarlanırlar. Günümüz şartlarında endüstriyel amaçlı kullanılabilecek pek çok enerji kablosu mevcuttur; bu alandaki çalışmalar, kablo akım taşıma kapasitelerini arttırmaya yönelik olarak sürdürülmektedir [15]. Üretici firmalar; çok farklı türde kesit alanına, kesit geometrisine ve yalıtım kapasitesine sahip enerji kablosu seçenekleri sunmaktadır; ayrıca, yüksek 
frekanslı AC sinyalleri taşımak amacıyla üretilmiş özel tip kablolar da üretilmiştir.

Tarihsel gelişim sürecinde, indüksiyon bobin tasarımında kullanılmış ilk kablo türleri, dairesel kesitli tek damarlı veya çok damarlı bakır iletkendir. Sonraki yıllarda dikdörtgen veya kare kesitli bakır iletkenler kullanılmıştır [16-19]. İndüksiyon 1sıtma sistemlerinde oluşan en temel problem, yüksel frekanslı akımın indüksiyon bobin sargıları üzerinde oluşturduğu deri etkisi (skin effect) ve yakınlık etkisi (proximity effect) dir. Bu etkiler sonucunda akım, sargıların dış yüzeyindeki belirli bir bölgeye yoğunlaşma eğilimi göstermekte ve dolayısıyla, bakır sargı kesitinin tümü akım tarafindan etkin olarak kullanılamamaktadır. Bu olumsuz etkiler dikkate alınarak, daha sonra ylllarda indüksiyon bobin tasarımı için, içi boşaltılmış silindirik bakır borular kullanılmıştır $[9,20]$. Yüksek güçlü indüksiyon 1sıtma sistemlerinde açığa çıkan 1s1, indüksiyon bobin sargılarını da isıtarak olumsuz etkilemektedir; bu olumsuz etki, içi boşaltılmış bakır boru içinden soğutma sıvısı geçirilerek önlenmiş ve daha verimli bir çalışma sağlanmıştır. Bu yöntem, günümüzde de sıkça kullanılmaktadır. Son olarak, deri ve yakınlık etkilerinin oluşturduğu problemleri aşmak için, indüksiyon bobin sargıları Litz kablosundan imal edilmiştir $[11,21,22]$. Litz kablosu, her biri yalıtılmış ince bakır iletkenlerden birçoğunun demet haline getirilmesiyle oluşturulmuş özel bir kablodur.

İndüksiyon Sıv1 1sitma sistemlerinin performans1, indüksiyon bobininin yapısıyla yakından ilişkilidir. Yüksek frekanslı uygulamalarda daha belirgin hale gelen deri ve yakınlık etkilerinin olumsuz yönlerini aşmak, 1S1 problemlerini çözmek ve daha yüksek performans sağlamak amacıyla, farklı yapıdaki enerji kablosu araştırmaları devam etmektedir. Bu çalışmada; günümüzde var olan ve indüksiyon sıvı 1sıtma sistemlerinde kullanılmış veya kullanılabilecek tüm kablo türleri araştırılmış, bu kabloların üç boyutlu (3B) katı modelleri oluşturulmuş, seçilen kablolar kullanılarak oluşturulmuş indüksiyon bobinlerinin aynı çalışma koşullarında iki boyutlu (2B) manyetik analizleri yapılmış ve indüksiyon sıvı 1sıtıcıların farklı çalışma frekanslarında ürettikleri 1sı gücü hesaplanarak performans testi yapılmıştır. Manyetik analiz ve performans testleri için, grafiksel kullanıcı arayüzlü modellemesimülasyon paket programı olan COMSOL ${ }^{\circledR}$ Multiphysics yazılımı kullanılmıştır. Bu çalışma ayrıca; tasarımcı ve üretici firmalara, farklı çalışma frekansları için, indüksiyon bobini üretiminde kullanılabilecek en verimli kablo türünün seçiminde yardımcı olmayı da amaçlamaktadır.

\section{INDÜKSIYON ISITMA TEMEL DENKLEMLERI VE DERİ ETKÍSI}

Genel olarak indüksiyon 1sitma, manyetik bir malzemenin değişken bir manyetik alana maruz bırakılarak üzerinde gerilim indüklenmesi ve bu gerilimin oluşturacağı yüksek eddy akımlarının manyetik malzemeyi ısıtması ile sağlanır. Bir ortamdaki elektromanyetik alan dağılımı Eş. 1 ve Eş.2 ile tanımlanabilir;

$$
\begin{aligned}
& \nabla \times\left(\mu^{-1} \nabla \overrightarrow{\mathrm{A}}\right)=\overrightarrow{J_{e}}-\sigma \frac{\partial \overrightarrow{\mathrm{A}}}{\partial t} \\
& \overrightarrow{\mathrm{E}}=-j \omega \overrightarrow{\mathrm{A}}-\nabla V
\end{aligned}
$$

burada; $\overrightarrow{\mathrm{A}}$ manyetik vektör potansiyel $[\mathrm{Wb} / \mathrm{m}], \overrightarrow{J_{e}}$ harici uygulanan akım yoğunluğu $\left[\mathrm{A} / \mathrm{m}^{2}\right], \overrightarrow{\mathrm{E}}$ elektrik alan şiddeti $[\mathrm{V} / \mathrm{m}], V$ skaler elektrik potansiyeli $[\mathrm{V}], \sigma$ elektriksel iletkenlik [S/m], $\mu$ manyetik geçirgenliktir $[\mathrm{H} / \mathrm{m}]$.

Alternatif değişim gösteren elektromanyetik alanın indüklemiş olduğu eddy akımları Eş. 3 ile; ve indüklenmiş eddy akımlarının sebep olduğu 1sı kayıpları da Eş.4 ile hesaplanabilir.

$\vec{J}=j \omega \sigma \overrightarrow{\mathrm{A}}$

$Q=\frac{[\sigma]^{-1} \vec{J} \vec{J}^{*}}{2}$

Eddy akımlarının açığa çıkarmış olduğu 1sı, iş-parçasının diğer bölgelerine ve iş-parçasının içinde bulunduğu ortama yayılacaktır. Zamana bağlı olarak iş-parçası üzerinde oluşan 1S1 dağılımı, klasik ısı akış denklemiyle tanımlanabilir (Eş.5);

$\rho C \frac{\partial T}{\partial t}+\nabla(-k \nabla T)=Q$

burada; $k$ termal iletkenlik (W/(m.K)); $T$ sicaklık (K); $\rho$ yoğunluk $\left(\mathrm{kg} / \mathrm{m}^{3}\right)$; $C$ özgül ısı kapasitesidir $(\mathrm{J} /(\mathrm{kg} . \mathrm{K}))$.

İndüksiyon 1sıtma işleminin herhangi bir iş-parçası üzerinde verimli bir şekilde gerçekleştirilebilmesi için, eddy akımlarını oluşturan manyetik alanın frekansı ve malzeme özelliklerinin uygun değerlerde olması gereklidir. Eddy akımları, doğası gereği, iş-parçasının yüzeyine doğru yoğunlaşma eğilimindedir; bu duruma kısaca "deri etkisi" denir. Yüksek frekanslı uygulamalardaki eddy akımları, deri etkisi neticesinde, iş-parçasının yüzeyinde yoğunlaşacaktır ve iç bölgelerdeki eddy akımları ihmal edilebilir düzeyde kalacaktır. Bunun sonucunda iş-parçasının etkin direnci artmış ve açığa çıkan 1sı, iş-parçasının yüzeyine yoğunlaşmış olacaktır. Isıtma derinliği, çalışma frekansına ve iş-parçasının elektriksel direnç ve bağıl manyetik geçirgenliğine bağlıdır. 
Pratik uygulamalar için 1sıtma derinliği, ortaya çıkan gücün yaklaşık olarak \%86'sı kadar değerinin açığa çıktığı derinlik değeri olup Eş.6 ile hesaplanabilir; burada, $\delta$ isıtma derinliği $(\mathrm{mm}), \omega$ manyetik alanın açısal değişim hızı $(\mathrm{rad} / \mathrm{s}), \mu$ işparçasının manyetik geçirgenliği $(\mathrm{H} / \mathrm{m})\left(\mu=\mu_{0} . \mu_{r}\right), \sigma$ iş-parçasının elektriksel iletkenliği $(\mathrm{S} / \mathrm{m})$ dir.

$$
\delta=\sqrt{\frac{2}{\omega \mu \sigma}}
$$

Silindirik bir iş-parçasında, ssıtma derinliğine göre normalize edilmiş eddy akımları ve toplam ısıtma gücü değişimleri Şekil.2.a'da verilmiştir; şekle göre, değişken manyetik alanın 1sitıcı aparat üzerinde oluşturduğu ssitma gücünün büyük bir kısmı, aparat yüzeylerine yakın bölgede açı̆̆a çıkmaktadır [19]. Bu durum, manyetik analiz programı yardımıyla 3B katı model üzerinde de gösterilmiş olup, ısıtıcı aparat üzerinde indüklemiş olan eddy akımlarının vektörel ve yüzey yoğunluklu gösterimi Şekil.2.b'de verilmiştir.

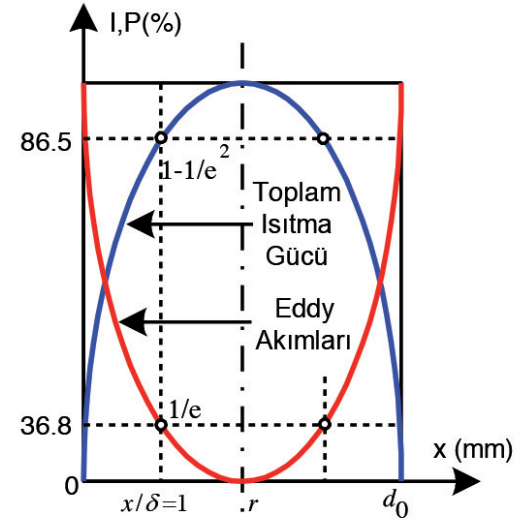

(a)

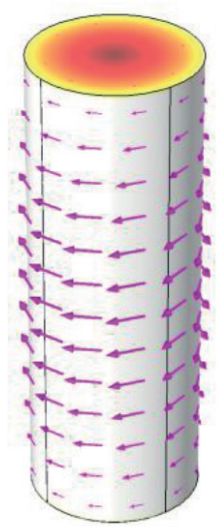

(b)
Şekil 2. Silindirik bir parça için; a) Isıtma derinliğine göre normalize edilmiş eddy akımları ve toplam ısıtma gücü değişimleri, b) Isıtıcı aparat üzerinde indüklenmiş olan eddy akımlarının vektörel ve yüzey yoğunluklu gösterimi.

\section{MATERYAL VE METOT}

İndüksiyon 1sıtma sistemlerinde, sürekli akan sıvılar için 1sıtma sağlayabilecek indüksiyon bobin tasarımı için birçok kablo türü mevcuttur. Bu kablolar kullanılarak oluşturulmuş indüksiyon bobininin performans analizini deneysel olarak yapmak oldukça zor ve zahmetli bir yöntemdir. Çünkü tüm çevresel faktörlerin ve çalışma şartlarının eşit koşullarda tutulması, istenen fiziksel boyutlarda kablo üretimi veya temini, kabloya ait tüm elektriksel özelliklerin eşit olması, performans ölçüm sistemlerine ihtiyaç duyulması, tasarım ve süreç maliyeti vb. gibi zorluklar mevcuttur. Bu zorlukları aşmak için bilgisayar tabanlı modelleme ve simülasyon paket programlarından faydalanmak uygun bir yöntemdir. $\mathrm{Bu}$ yüzden, modeli oluşturulan indüksiyon bobinlerinin performans analizini gerçekleştirmek için COMSOL ${ }^{\circledR}$ Multiphysics yazılımı kullanılmıştır. Sonlu elemanlar yöntemi (FEM) ve kısmi diferansiyel denklemler (PDE) ile çözüm üreten COMSOL programı, farklı programlar (Matlab, AutoCad, Catia, Solid-Works, vb.) ile etkileşimli çalışabilen güçlü bir modelleme ve simülasyon paket programıdır ve birçok mühendislik bilim dalında sıkça kullanılmaktadır [23,24]. Yazılım, indüksiyon 1sitma ile ilgili birçok çalışmada da kullanılmıştır [17,18,25].

İndüksiyon bobin tasarımında kullanılabilecek iletken türleri araştırıldığında, genel olarak 8 farklı kablo tipine ulaşılmıştır. Farklı tip bu kablolar kullanılarak COMSOL 3B modelleme ortamında oluşturulan indüksiyon bobinleri Şekil.3'te verilmiştir. Bu bobinlerin ortak özelliği; eşit iç silindirik çap ve yüksekliğe, eşit toplam kablo kesit değerine (K2 ve K6 hariç) ve eşit manyeto-motor-kuvvet (mmk) değerine sahip olmalarıdır. Şekil.3.a'da verilen K1 modeli, tek damarlı dairesel kesitli silindirik bakır kablodan 6 sipir sarılarak üretilmiş indüksiyon bobin modelidir; kablo yarıçapı $7.3 \mathrm{~mm}$ olup kablo kesiti $167.4 \mathrm{~mm}^{2}$ olarak hesaplanmıştır. Şekil.3.b'de verilen K2 modeli, yüksek frekanslı uygulamalarda kullanmak ve aynı zamanda soğutma sağlamak amacıyla K1 modelinin içinin boşaltılmış versiyonudur. Çok telli konsantrik iletkenden 5 sipir sarılarak üretilen K3 indüksiyon bobin modeli Şekil.3.c'de verilmiştir; 19 adet $10.52 \mathrm{~mm}^{2}$ lik iletkenlerden oluşan bu kablo, K1 modeline göre daha esnek bir yapıya sahiptir. Şekil.3.d'de verilen K4 modeli, dikdörtgen kesitli bakır lamadan tek sipir olarak üretilmiş indüksiyon bobinini temsil etmektedir; kesit kenar uzunlukları $10 \mathrm{~mm} / 100 \mathrm{~mm}$ olan kablo, $1000 \mathrm{~mm}^{2}$ lik kesit alanına sahiptir. Dikdörtgen kesitli kablodan 6 sipir sarılarak oluşturulan K5 indüksiyon bobin modeli Şekil.3.e'de verilmiştir; kenar uzunlukları $11.1 \mathrm{~mm} / 15 \mathrm{~mm}$ olan kablo, $166.5 \mathrm{~mm}^{2}$ lik kesit alanına sahiptir. Yüksek frekanslarda kullanmak ve soğutma sağlamak amacıyla K5 modelinin içinin boşaltılmasıyla elde edilen K6 indüksiyon bobin modeli Şekil.3.f'de verilmiştir. Şekil.3.g'de verilen K7 modeli, ince kesitli bakır yaprak levhadan 6 sipir sarılarak oluşturulmuş indüksiyon bobin modelidir; levha kalınlığı $1.67 \mathrm{~mm}$ olarak seçilmiştir. $2.164 \mathrm{~mm}^{2}$ lik demet iletkenlerden 5sipirlik Litz kablosu olarak sarılmış K8 indüksiyon bobin modeli Şekil.3.h'da verilmiştir; silindirik kesite sahip Litz kablosu demetinde 91 bağımsız iletken bulunmaktadır. 
K1

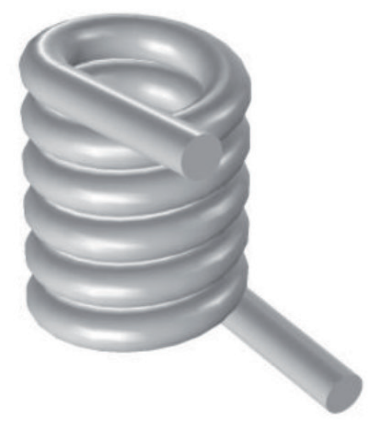

(a)

K5

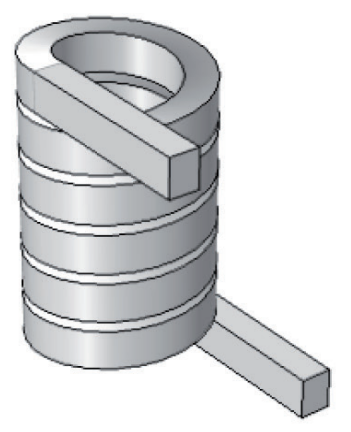

(e)
K2

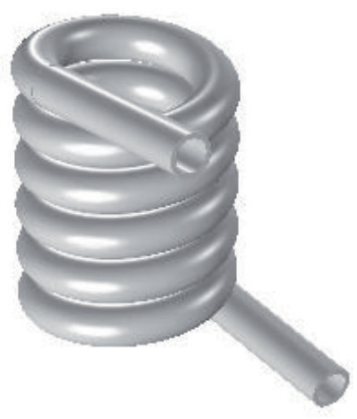

(b)

K6

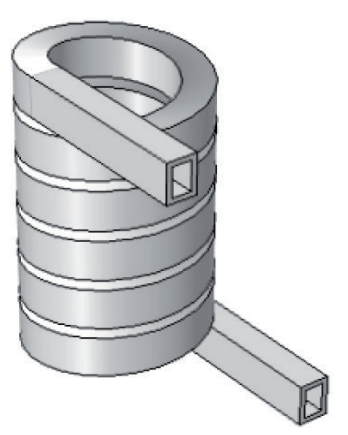

(f)
K3

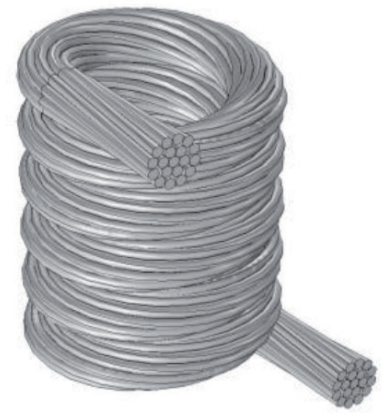

(c)

K7

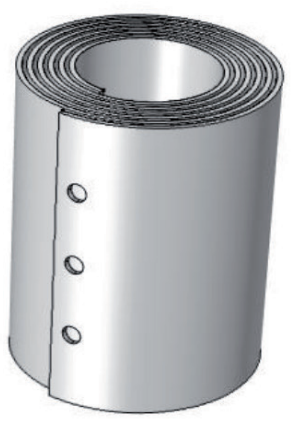

(g)
K4

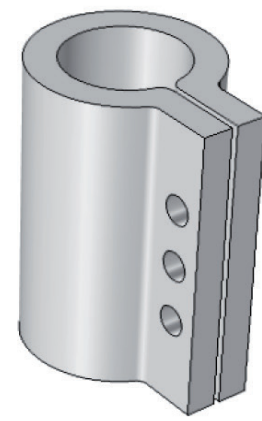

(d)

K8

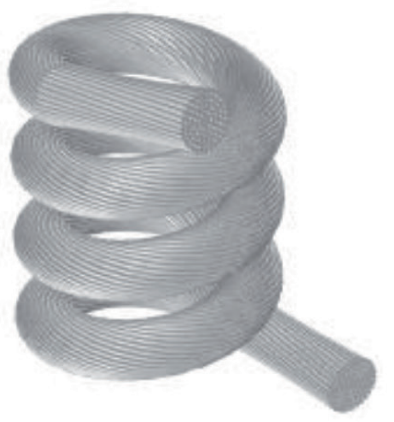

(h)

Şekil 3. Farklı tip kablolar kullanılarak COMSOL 3B modelleme ortamında oluşturulan indüksiyon bobinleri

İndüksiyon bobinleri eksenel simetrik yapıya sahip oldukları için, manyetik analizler ve performans testleri '2B Axisymmetric' ortamda gerçekleştirilmiş̧tir. 3B modelleme ortamı, her türlü modelin oluşturulmasına imkân sağlasa da, simülasyon için oluşturulacak ağ (mesh) yapı elemanlarının sayısını, bilgisayar hafiza gereksinimini ve model çözüm süresini ciddi oranda arttırmaktadır; bu yüzden modellemeler için 2B ortam tercih edilmiştir. 2B Axisymmetric çizim ortamında oluşturulan indüksiyon bobinlerinin simülasyonları, sayısal ve grafiksel verilerin elde edilmesi için, COMSOL ${ }^{\circledR}$ Multiphysics programının 'Magnetic Fields (MF)', 'Heat Transfer in Solid (HT)' ve 'Fluid-Laminar Flow (SPF)' fizik modülleri kullanılmıştır.

\subsection{Sistem Tanıtımı, Fiziksel Boyutlar ve Kabuller}

İndüksiyon 1sıtma sistemi üç ana unsurdan oluşmaktadır; bunlar: ısıtılacak sıvıyı taşıyacak olan plastik (paramanyetik) boru, indüksiyon 1sitma aparatı ve indüksiyon bobinidir. Sıvıyı taşıyacak olan plastik borunun iç ve dış yarıçapları sırasıyla $16 \mathrm{~mm}$ ve $19 \mathrm{~mm}$ olarak seçilmiştir. Isıtıcı aparat olarak, içi dolu silindirik manyetik malzeme kullanılmış olup yüksekliği $100 \mathrm{~mm}$ ve yarıçapı $12 \mathrm{~mm}$ 'dir. İndüksiyon bobinlerinin maksimum yüksekliği, 1 sıtıcı aparat yüksekliğiyle eşit değerde olup 100mm'dir; 1sıtma aparatına eşit yakınlığı sağlamak için tüm indüksiyon bobin iç yarıçapları r=20mm olarak seçilmiştir; dış yarıçaplar, iletken türüne göre değişiklik arz etmektedir. Bobinde kullanılan net toplam bakır kesiti $1000 \mathrm{~mm}^{2}$ olarak seçilmiştir.

İndüksiyon bobinlerinin eşit etkin değerdeki manyetomotor-kuvvete $\left(\mathcal{F}_{m m k}=2000 \mathrm{As}\right)$ sahip olduğu kabul edilmiştir. Performans kıyaslamasına olanak sağlayabilen eşit kesite sahip indüksiyon bobinleri oluşturmak amacıyla, kullanılan iletken geometrisine uygun olarak 1-4-6 sipirlik sarg1 kullanılmıştır. Isıtma aparatının yüzeyinde oluşan 1sıyı akan siviya kolayca iletmek ve 1sının, plastik boruya verebileceği zararı önlemek için, 1sıtma aparatı ile boru arasına $4 \mathrm{~mm}$ boşluk bırakılmıştır. Böylece, sıvının akış yolu üzerine konulan 1sıtma aparatının kesit alanı $452 \mathrm{~mm}^{2}$ ve 
boru iç kesit alanı $804 \mathrm{~mm}^{2}$ seçilerek, sıvı için $352 \mathrm{~mm}^{2}$ lik bir akış yolu kesiti bırakılmıştır. Isıya maruz kalmadığı için indüksiyon bobin sargı direncinin sıcaklıkla değişmediği kabul edilmiştir. Simülasyon çözümleme bölgesi, $300 \mathrm{~mm}$ çap ve $800 \mathrm{~mm}$ yüksekliğe sahip içi hava dolu bir silindir ile sınırlandırılmış; dış sınır yüzeyler, manyetik yalıtkan malzeme olarak tanımlanmıştır $(n \times \vec{A}=0)$. Bazı durumlarda çözümleyicide yakınsama (converging) problemlerine sebep olan hava'nın elektriksel iletkenliği, çözümü etkilemeyecek şekilde $\sigma_{\text {hava }}=1 \mathrm{~S} / \mathrm{m}$ olarak alınmıştır.

\subsection{Bölge (Domain) ve Sınır (Boundary) Koşulları}

İndüksiyon bobinlerinin performans testlerini gerçekleştirmek için aynı çalışma koşullarının sağlanması gereklidir. Bu amaçla, indüksiyon ısıtma simülasyonlarında, aynı özelliklere sahip ferromanyetik malzeme kullanmak için ısıtma aparatları 'demir' (Iron) olarak tanımlanmıştır. Manyetik malzemelerin bağıl manyetik geçirgenliği sıcaklık ile ters orantılı olarak değişmektedir; bu yüzden, ısıtma aparatının bağıl manyetik geçirgenliği çalışma sıcaklığına göre tespit edilmelidir. Isttılacak olan sivı, su olarak alınırsa, kaynama noktası ve dolayısıyla 1sitma aparatının çalışma sıcaklığı en fazla $100^{\circ} \mathrm{C}$ olacaktır. Bu yüzden, 1sıtma aparatı olarak seçilen demir malzemenin $100^{\circ} \mathrm{C}$ 'deki bağıl manyetik geçirgenliği $\mu_{r}=3850$ olarak girilmiştir; demir malzemenin elektriksel iletkenliği, düşük 1sılar için değişmediği kabul edilerek $\sigma=1.12 e 7 \mathrm{~S} / \mathrm{m}$ olarak alınmıştır. İndüksiyon bobinlerine, 'bakır' (copper) malzeme özellikleri atanmış olup elektriksel iletkenlik $\sigma=5.998 e 7 \mathrm{~S} / \mathrm{m}$ ve bağıl manyetik geçirgenlik olarak kabul edilmiştir. İndüksiyon bobinlerine herhangi bir yöntemle soğutma uygulandığ1 için 1sınmadıkları ve iç ohmik dirençlerinin sıcaklıkla değişmediği varsayılmıştır. Manyetik analiz, tüm indüksiyon bobinleri için 'Frequency-Stationary' çalışma tipi ve frekans tabanlı parametrik çözüm kullanılarak gerçekleştirilmiştir.

COMSOL programı, modellenmiş olan tüm fiziksel sistemleri, sonlu elemanlar yöntemine (FEM) göre sonlu parçalara ayırıp; modelin fiziksel boyutlarını, model bölge özelliklerini, sınır koşullarını, giriş-çıkış parametrelerini, modelde kullanılan malzeme özelliklerini (manyetik, elektriksel, 1sısal, vb.), çözüm-çözümleyici türünü ve kullanılan fizik modülündeki yapısal denklemleri kullanarak bir çözümleme yapmaktadır. Manyetik alanlar (MF) fizik modülünün kullanmış olduğu yapısal denklemler Eş.8'de verilmişsir.

$$
\left(j \omega \sigma-\omega^{2} \varepsilon_{0} \varepsilon_{r}\right) \overrightarrow{\mathrm{A}}+\nabla \times \overrightarrow{\mathrm{H}}=\overrightarrow{J_{e}} \quad \overrightarrow{\mathrm{B}}=\nabla \times \overrightarrow{\mathrm{A}}
$$

Fiziksel modeli sonlu parçalara ayırma işlemi, belirtilen özelliklerde ağ örgüsü oluşturmakla sağlanmaktadır. Ağ örgüsünün kalitesi (parça sayısı), simülasyon çözüm sonuçlarını ve çözüm süresini etkilemektedir; bu yüzden modelde, aynı kalitede ağ örgüsü oluşturmak amacıyla, 1sitıc1 aparat bölgesinde en büyük ağ boyutu $1 \mathrm{~mm}$ ile sınırlandırılmıştır; diğer bölgelerdeki mesh kalitesi iyi-kalite (fine) olarak ayarlanmıştır. İndüksiyon bobin geometrik şekillerinin çok farklı yapıda olması, eşit sayıda parça (element) sayısına bölünmesine imkân tanımamaktadır.

Isıtıcı aparatların dış sınır bölgelerine, 'Empedans Sınır Koşulu' (Impedance Boundary Condition) atamas1 yapılmıştır. Bu sınır koşulu, manyetik alanların bu sınırlardan içeriye çok az girişim yapabildiği, diğer bir deyişle, eddy akımlarının sadece aparat yüzeylerinde akabileceğini belirtmektedir. Empedans Sınır Koşulu, yüksek frekanslı indüksiyon 1sitma uygulamalarındaki deri etkisini en iyi şekilde modelleyebilmekte ve simülasyon çözüm süresini ciddi oranda kısaltabilmektedir.

Model bünyesindeki indüksiyon bobin bölgeleri, silindirik yapıda sarılmış tek-sipirli bobin (Single-Turn Coil) ve/veya bobin grubu (Coil Group) bölge özelliğine sahiptir. Bu sayede tüm bobin parametreleri (direnç, endüktans, empedans, gerilim, güç, vb.) kolaylıkla hesaplanabilecektir. Tüm modellerdeki indüksiyon bobin beslemesi, akım kaynağından sağlanmıştır. Belirtilen tüm bu koşullar altında, K1 tipi indüksiyon bobini kullanılarak katı modeli oluşturulan indüksiyon sıvı 1sıtıcısının 3B görüntüsü Şekil.3.a'da, 2B Axisymmetric ortamda manyetik analiz için oluşturulan model Şekil.3.b'de ve ăg yapısı Şekil.3.c'de verilmiştir.

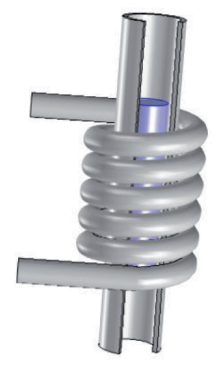

(a)

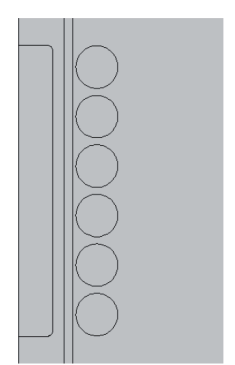

(b)

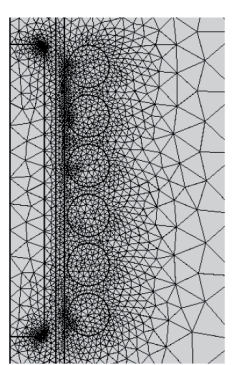

(c)
Şekil 4.a) K1 tip indüksiyon bobininin kullanıldığ 1 indüksiyon sıvı 1sıtıcının 3B görüntüsü, b) 2B Axisymmetric ortamda oluşturulan K1 modeli, c) K1 modeline ait ağ yapıs1

\section{SİMÜLASYON SONUÇLARI}

Tasarım prensipleri, çalışma koşulları, kullanılan malzemelerin elektriksel-manyetik özellikleri, belirlenen fiziksel ölçüler ve bazı kabuller çerçevesinde; daha önce 
Şekil.3'te verilen farklı tipteki kablolar kullanılarak tasarımı gerçekleştirilen indüksiyon bobin modelleri, aynı çevresel faktörleri sahip indüksiyon ısıtıcının dışına konumlandırılarak 2B manyetik analizler gerçekleştirilmiştir. İndüksiyon bobinlerinin performans analizi, COMSOL bünyesinde bulunan entegrasyon hesaplayıcı yardımıyla, 1sıtıcı aparat yüzeyinde açığa çıkan 1sı gücü (mf.Qsrh) hesap edilerek gerçekleştirilmiştir. Aparat üzerinde açığa çıkan 1sı gücü, aynı zamanda akışkan sıvıya transfer edilecek ola 1s1 gücüne de eşittir. İndüksiyon bobinlerinin $\mathrm{f}=10 \mathrm{kHz}$ çalışma frekansı için, 2B eksenel simetri çizim modundaki manyetik
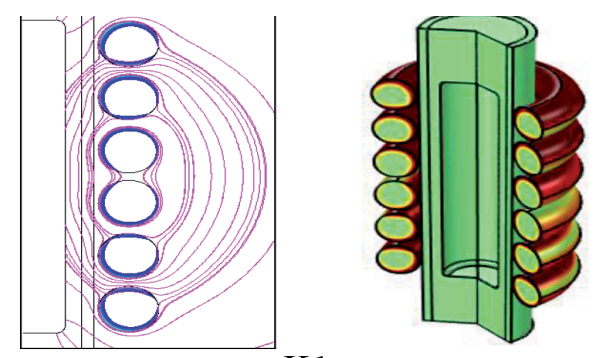

K1
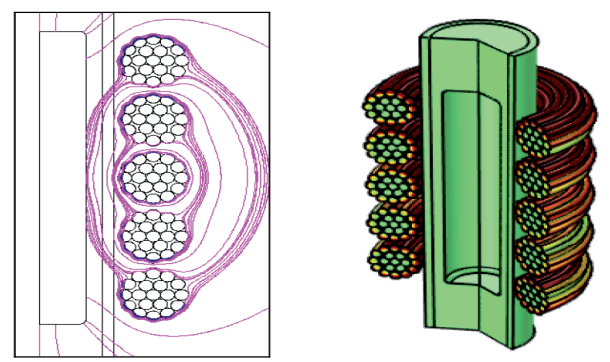

K3
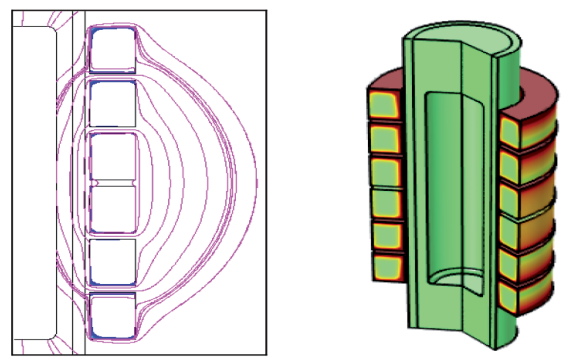

K5
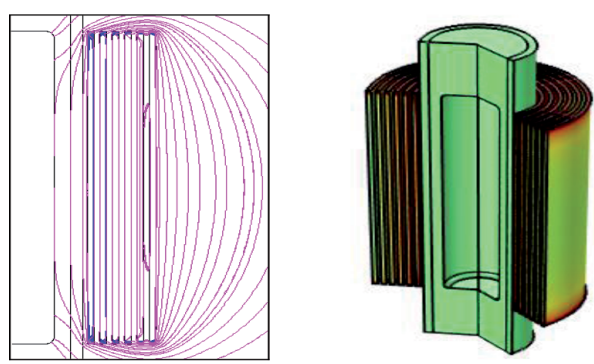

K7 analiz sonuçları ve 3B gösterimi Şekil.5'de verilmiştir; 2B şekillerde kablo kesiti üzerindeki renklendirmeler 'akım yoğunluğunu' ve çizgisel hatlar 'manyetik akıyı' temsil etmektedir; 3B şekillerdeki renklendirmeler 'akım yoğunluğunu' belirtmektedir. Şekil.5'deki tüm modellerde bobin akımının, deri etkisinden dolayı iletkenlerin dış yüzeyine yoğunlaştı̆̆ 1 ve yakınlık etkisinden dolayı da iletken dış yüzeylerine simetrik olarak dağılmadığı açıkça görülmektedir; daha yüksek çalışma frekanslarında bu etkiler çok daha belirgin hale geldiği için, bobin akımları iletken yüzeyinde çizgisel şekilde oluşmaktadır.
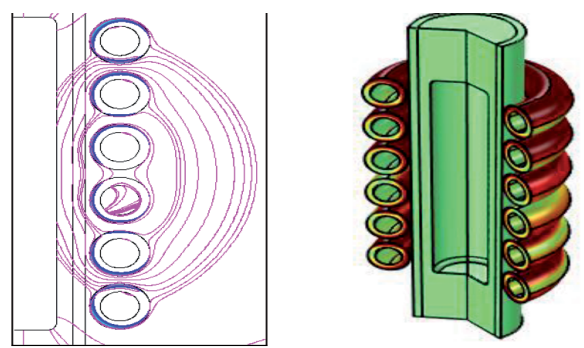

K2
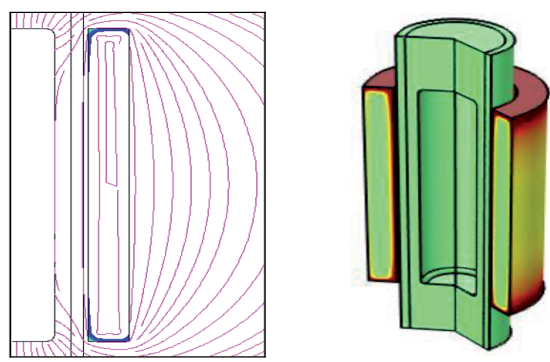

K4
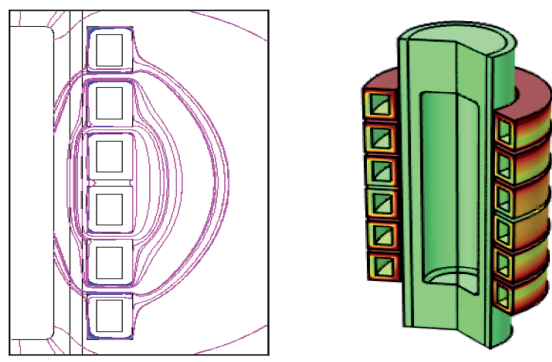

K6
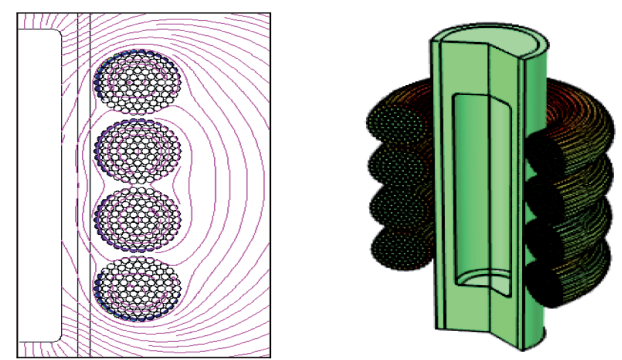

K8

Şekil.5. İndüksiyon bobinlerinin manyetik analiz sonuçları 
İndüksiyon bobin modellerinin performanslarına ilişkin simülasyon sonuçları Tablo.1'de verilmiştir. Tablo.1, 8 farklı kablodan imal edilen indüksiyon bobinlerinin, 11 farklı çalışma frekansında üretmiş oldukları güçleri içermektedir; parametrik manyetik analiz için gerekli olan çalışma frekansları, $10 \mathrm{kHz}$ ve $1 \mathrm{MHz}$ arasında logaritmik bir artışla tanımlanmıştır. Tablo.1'de verilen sonuçlara göre; bu çalışmada belirtilen tasarım kriterlerine göre en iyi performansa sahip indüksiyon bobin tipi $\mathrm{K} 8$ türüdür. Litz kablosundan üretilen K8 tipi indüksiyon bobini, deri ve yakınlık etkisinin olumsuz yönlerini azaltarak en fazla indüksiyon 1sıtma gücünü sağlamıştır; Litz kablosunun performans1, yüksek frekanslarda daha da belirgin hale gelmektedir. İkinci sıradaki en iyi performans, aynı güçlere sahip olan K1 ve K2 modellerine aittir; bu sonuç, benzer geometrik şekle sahip olan bu iletkenler için beklenen bir durumdur. Bu modelleri sırasıyla, çok az bir farkla K3, K5 ve K6 türleri izlemektedir. K5 ve K6 tipi modeller de yine, benzer geometriye sahip oldukları için, hemen hemen eşit indüksiyon 1sıtma gücünü sağlamıştır. Tek sipirlik sargıdan oluşan K4 tipi ve ince kesitli bakır levhadan üretilen K7 tipi modeller daha düşük performans değerlerine sahiptir. Tablo.1'de verilen simülasyon sonuçları, Şekil.6'da grafiksel olarak ta verilmiştir; K1, K2 ve K3 tipleri yakın güç değerlerine sahip oldukları için grafikler çakışık durumda oluşmuştur; benzer durum, K5 ve K6 tipleri için de geçerlidir.

Tablo 1. İndüksiyon bobin performanslarına ait simülasyon sonuçları

\begin{tabular}{ccccccccccccc}
\hline İndüksiyon & & \multicolumn{7}{c}{ Farklı Frekans Değerleri için İndüksiyon Isıtma Güçleri (Watt) } \\
Bobin Tipi & $10 \mathrm{kHz}$ & $15.85 \mathrm{kHz}$ & $25.12 \mathrm{kHz}$ & $39.81 \mathrm{kHz}$ & $63.1 \mathrm{kHz}$ & $100 \mathrm{kHz}$ & $158.5 \mathrm{kHz}$ & $251.2 \mathrm{kHz}$ & $398.1 \mathrm{kHz}$ & $631 \mathrm{kHz}$ & $1 \mathrm{MHz}$ \\
\hline K1 & 2412 & 3732 & 5618 & 8235 & 11777 & 16476 & 22613 & 30539 & 40688 & 53602 & 69937 \\
K2 & 2412 & 3732 & 5618 & 8235 & 11777 & 16477 & 22615 & 30540 & 40689 & 53602 & 69936 \\
K3 & 2378 & 3689 & 5566 & 8174 & 11710 & 16404 & 22539 & 30463 & 40606 & 53508 & 69821 \\
K4 & 1871 & 2992 & 4650 & 7019 & 10307 & 14756 & 20653 & 28348 & 38272 & 50956 & 67048 \\
K5 & 2172 & 3401 & 5184 & 7696 & 11137 & 15748 & 21814 & 29687 & 39802 & 52700 & 69041 \\
K6 & 2172 & 3401 & 5184 & 7695 & 11136 & 15745 & 21809 & 29679 & 39786 & 52670 & 68985 \\
K7 & 1634 & 2639 & 4128 & 6255 & 9210 & 13218 & 18546 & 25516 & 34520 & 46046 & 60655 \\
K8 & 2729 & 4219 & 6338 & 9270 & 13221 & 18445 & 25246 & 33999 & 45169 & 59334 & 77197 \\
\hline
\end{tabular}

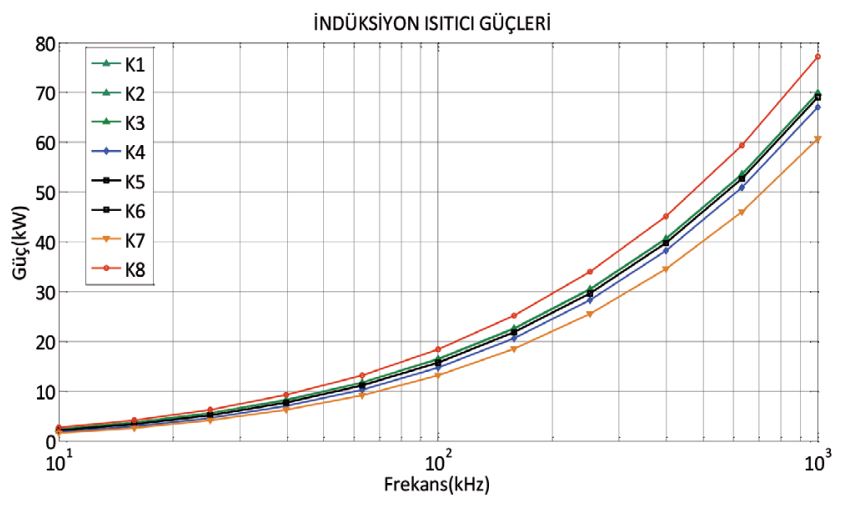

Şekil.6. İndüksiyon bobin tiplerinin performans grafiği

Son aşamada, tasarımı yapılan indüksiyon bobinlerinin, sıvı akış yoluna konumlandırılan 1sıtma aparatı üzerinde oluşturdukları 1sıtma gücü ve akışkan sıvı içindeki çalışma şekli ‘Fluid-Laminar Flow' fizik modülü ile simüle edilmiştir. Simülasyonda sıvı olarak $5 \mathrm{~cm} / \mathrm{s}$ akış hızına sahip su (liquid water) kullanılmıştı;; su akış haznesindeki tüm yüzeylerin sabit durduğu (wall) ve sürtünmeli olduğu (no slip), boru dış çeperinin termal yalıtkan olduğu kabul edilmiştir. Bu şartlar altında, $\mathrm{K} 1$ tipi indüksiyon bobininin $\mathrm{f}=10 \mathrm{kHz}$ için elde edilen simülasyon sonuçları Şekil.7'de verilmiştir. Şekil.7a'da, boru içinde tanımlanmış olan sıvının 3B akış hız grafiği verilmiştir; 1sitıcı aparatın bulunduğu ve kesitin daraldığı bölgede, sıv1 akış hızının artmış olması beklenen bir sonuçtur; 1sıtıcı aparat çeperinde sıvı akış hızı $16 \mathrm{~cm} / \mathrm{s}$ 'ye kadar yükselmiştir. Şekil.7b'de, 1sıtıcı aparatın akışkan sıvıyı 1sıtma şekline ait kesit görüntü verilmiştir. Sıvı giriş sıcaklığ $20^{\circ} \mathrm{C}$ olarak tanımlanmıştır. Isıtıcı aparat yüzeyindeki maksimum sıcaklık değeri $160^{\circ} \mathrm{C}$ olarak hesaplanmıştır. $5 \mathrm{~cm} / \mathrm{s}^{\prime}$ lik akış hızına sahip sıvının, ısıtıcı aparat üzerindeki ısıyı alarak uzaklaştı̆̆ı ve borunun merkezine doğru yoğunlaştığı açıkça görülmektedir. Daha yüksek çalışma sıcaklıkları elde etmek için, daha yüksek çalışma frekansları veya daha düşük sıvı akış hızları kullanılmalıdır. 


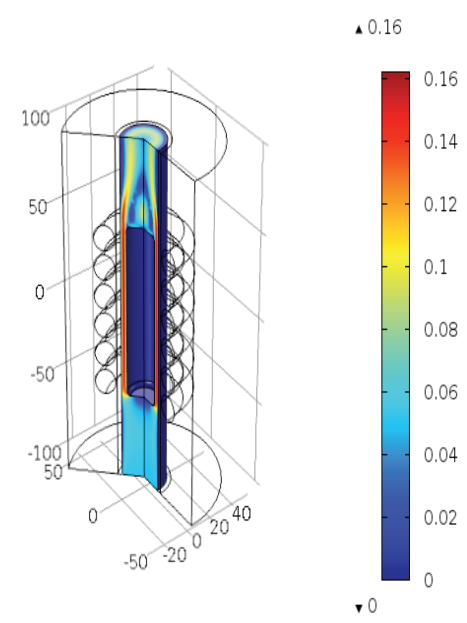

(a)

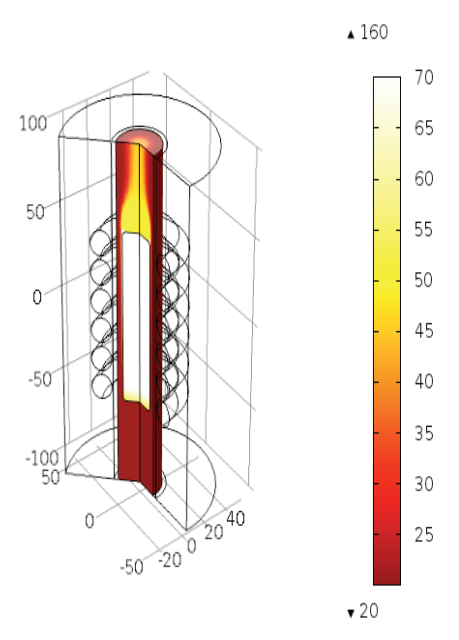

(b)

Şekil 7. K1 tipi indüksiyon bobinine ait S1V1 1sıtma simülasyon sonuçları, a) Sıvının akış hızı grafiği, b) Isıtıcı aparatın akışkan sıvıyı ısıtma şekline ait kesit görüntü

\section{SONUÇ VE ÖNERÍLER}

İndüksiyon siv1 1sıtma sistemlerinin performansını etkileyen en önemli unsurlardan biri, yüksek frekanslı manyetik alanı sağlayacak olan indüksiyon bobinleridir. Günümüzde, indüksiyon bobin tasarımı için kullanılan (veya kullanılabilecek olan) iletken geometrileri çok fazla çeşitlilik arz etmektedir. Bu çalışmada, 8 farklı iletken türünden imal edilen indüksiyon bobinleri COMSOL® Multiphysics yazılımı ile 3B olarak modellenmiş, farklı çalışma frekansları için eşit koşullarda 2B Axisymmetric manyetik analizleri gerçekleştirilmiş ve performans değerleri hesaplanmıştır; hesaplanan sonuçlar tablo ve grafik ortamında verilmiştir. Bu sonuçlara göre, indüksiyon bobin tasarımında kullanılabilecek en verimli iletken türü Litz (K8) kablosudur. Tek damarlı dairesel kesitli silindirik kablolar (K1 ve K2) ve çok telli konsantrik kablo (K3) verimlilik açısından ikinci sırada yer almaktadırlar. Litz kablosunun diğerlerine göre üstünlüğü, orta ve yüksek çalışma frekanslarında daha belirgin hale gelmektedir; düşük çalışma frekanslarında, Litz kablosu ile diğerlerinin arasında çok belirgin bir fark görülmemektedir. Dikdörtgen kesitli kablolar (K4, K5, K6), her ne kadar doluluk (sıklık) oranı yüksek sargı oluşturmaya imkân tanısa da, indüksiyon 1sitma sitemlerinde orta dereceli bir performansa sahiptir. En düşük verimlilik, ince kesitli bakır levhadan üretilen K7 tipi indüksiyon bobinine aittir. Geometrik yapısı gereği üst üste sarılan sipirler ve sargı boşlukları, bobin akımının (ve dolayısıyla manyetik alanın) 1sıtıcı olarak kullanılan demir aparattan uzaklaşmasına sebebiyet vermiş ve isıtma gücünü azaltmıştır. İndüksiyon bobinlerinin performansını etkileyen diğer bir önemli parametre, bobin sargılarından geçen yüksek akımların oluşturduğu isı kayıplarıdır (joule heating). Bu 1S1 kayıpları, bazı durumlarda indüksiyon bobinlerinin soğutulmasını zorunlu kılmaktadır. $\mathrm{Bu}$ tip çalışma durumları için, geometrik yapısı gereği iyi bir soğutmaya imkân tanıyan K2 veya K6 tipi iletkenlerin indüksiyon bobin tasarımında kullanılması uygun olacaktır.

\section{KAYNAKLAR}

[1] Fairchild Semiconductor Inc. (2000). Induction Heating System Topology Review, Application Note, AN-9012.

[2] Rudnev, V.I. (2003), Handbook of Induction Heating, Marcel Dekker Inc..

[3] Zinn, S., Semiatin, S.L. (2002). Elements of Induction Heating, Design, Control, and Application, Electric Power Research Institute, Inc.

[4] Sadhu, P.K., Roy, D., Pal, N., (2015). Design and Implementation of High Frequency Inverter Operation for Induction Heating Cooking Application Using PSIM Software, Int. J. of Electronics \& Communication Technology (IJECT), 6(1), 130-133.

[5] Altıntaş, A., Yıldız, M.N., Kızılkaya, İ., (2012). İndüksiyon Isıtma Prensibi ile Çalışan Mikrokontrol Denetimli Bir Sıvı Isıtıcıs1 Tasarım1, Dumlupınar Üniversitesi, Fen Bilimleri Enstitüsü Dergisi, Cilt 29, 45-52.

[6] Al-Shaikhli, A.K.M., Meka, A.T., (2014). Design and Implementation of Practical Induction Heating Cooker, Int. J. of Soft Computing and Engineering (IJSCE), 4(4), 73-76.

[7] Sarnago, H., Lucia, O., Mediano, A., Burdio, J.M., 2013. Modulation Scheme for Improved Operation of a RB-IGBT Based Resonant Inverter Applied to Domestic Induction Heating, IEEE Trans. on Industrial Electronics, 60(5), 20662073. 
[8] Curran, J.S., Featherstone, A.M., (1988). Electric-Induction Fluid Heaters, Power Engineering Journal, 2(3), 157-160.

[9] Kenada, M., Hishikawa, S., Tanaka, T., Guo, B., Nakaoka, M., (1999). Innovative Electromagnetic Induction Eddy Current-Based Dual Packs Heater Using Voltage-Fed HighFrequency PWM Resonant Inverter for Continuous Fluid Processing in Pipeline, IEEE Engineering Technologies, Vol.2, 797-802.

[10] Nakamizo, T., Guo, B., Nakaoka, M., (1999). New Generation Electromagnetic Induction-Based Fluid-Heating Energy Processing Appliance Using Voltage-Fed PWM Resonant Inverter, Proceeding of PCIM-Tokyo, Japan, 597-607.

[11] Sadakata, H., Nakaoka, M., Yamashita, H., Omori, H., Terai, H., (2002). Development of Induction Heated Hot Water Producer Using Soft Switching PWM High Frequency Inverter, IEEE, PCC-Osaka-2002, Vol.2, 452-455.

[12] Nakamizo, T., Kenada, M., Hishikawa, S., Guo, B., Iwamoto, H., Nakaoka, M., (1999). New Generation Fluid Heating Appliance Using High Frequency Load Resonant Inverter, IEEE 1999 International Conference on Power Electronics and Drive Systems, PEDS'99, Hong Kong, Vol.1, 309-314, .

[13] Zhang S.J., Yang Z.Q., Zhao Q.H., (2004). Electromagnetic Water Heater, U.S. Patent, No: 6674055.

[14] Greis I., Ostlund A., (1984). Device for Heating Fluent Material Flowing Past Short-Circuited Heating, U.S. Patent, No: 4471191, Asea Ab.

[15] G.J. Anders, (2011). Rating of Electric Power Cables, Ampacity Computations for Transmission, Distribution and Industrial Applications, IEEE Press Power Engineering Series, Mc-Graw Hill Comp.

[16] Ahmed, T., Ogura, K., Chandhaket, S., Nakaoka, M., (2003). Asymmetrical Duty Cycle Controlled Edge Resonant Soft Switching High Frequency Inverter for Consumer
Electromagnetic Induction Fluid Heater , Automatica, ATKAAF 44(1-2), 21-26.

[17] Djellabi, K., Latreche, M.E.H., (2014). Induction Heating Process Design Using COMSOL ${ }^{\circledR}$ Multiphysics Software 4.2a , Int. J. of Electrical, Computer, Electronics and Communication Engineering, 8(1).

[18] Istardi, D., Triwinarko, A., (2011). Induction Heating Process Design Using COMSOL® Multiphysics Software, Telkomnika, 9(2), 327-334.

[19] http://www.dw-inductionheating.com/ induction $\% 20$ heating\%20coil\%20design.pdf, Dawei Induction Heating Machine Co.,Ltd (Erişim tarihi: 02.11.2015)

[20] Iatcheva I., Gigov G., Kunav G., Stancheva R., (2012). Analysis of Induction Heating System for High Frequency Welding, Facta Universitatis, Elec. Energ., 25 (3), 183-191.

[21] Sugimura H., Muraoka H., Ahmed T., Chandhaket S., Hiraki E., Nakaoka M., Lee H.W., (2004). Dual Mode Phase-Shifted ZVS-PWM Series Resonant High-Frequency Inverter for Induction Heating Super-Heated Steamer, Journal of Power Electronics, 4(3), 138-151.

[22] Roßkopf A., Bär E., Joffe C., (2014). Influence of Inner Skin and Proximity Effects of Conduction in Litz Wires, IEEE Transactions on Power Electronics, 29(10).

[23] Zimmerman, W.B.J., (2006). Multiphysics Modelling with Finite Element Methods, Series on Stability, World Scientific Pub., 432 p.

[24] Pryor, R.W., (2011). Multiphysics Modelling using COMSOL: A first principles approach, Jones \& Bartlett Pub., Mass., $852 \mathrm{p}$.

[25] Ernest, R., Perrier, D., Feigenblum, J., Hemous, R., (2006). 3D Inductive Phenomena Modelling, In The Proceeding of the COMSOL Users conference, Paris, 81-86. 